\title{
Dizer e Mostrar em Ludwig Wittgenstein
}

\author{
Edmilson Alves de Azevedo* \\ recebido: $05 / 2014$ \\ aprovado: 07/2014
}

\begin{abstract}
Resumo: Neste texto, vamos apresentar os elementos fundamentais da teoria da "representação" no pensamento de Ludwig Wittgenstein desde a sua concepção da lógica e da linguagem e dar consequências da distinção entre "mostrar e dizer" com o seu personagem central o autor pensou limites entre o que pode ser pensado com significado, e que não pode ser expressa por meio de proposições, tais como a filosofia baseada em problema.

Palavras-chave: Linguagem, Mostrar e Dizer, Lógica, Proposição, Pensamento.
\end{abstract}

Abstract: In this text, we will present the fundamental elements of the theory of 'representation' in the thought of Ludwig Wittgenstein from his conception of logic and language and give consequences from the distinction between "showing and saying" with its central character the author's thought boundaries between what can be thought of with meaning, and what cannot be expressed by means of propositions, such as the problem based philosophy.

Keywords: Language, Show and Tell, Logic, Proposition, Thought.

No Tractactus logicu-philosophicus, Witgenstein tentou resolver aquilo que constituía segundo pensava, o problema fundamental da filosofia: delimitar claramente, desde o interior, o âmbito do dizível e, ao mesmo tempo, implicitamente, do indizível. Ele pensava ter resolvido a questão e ter assim liquidado definitivamente com a filosofia; embora a solução obtida mostrava precisamente que tudo que se pode tentar legitimamente dizer em filosofia tinham sido, os problemas filosóficos considerados geralmente como os mais urgentes e os mais importantes, mas os Lebensproblems, não teriam nem mesmo aflorado.

\footnotetext{
* Universidade Federal da Paraíba - UFPB em@il: eazevedojp@gmail.com
} 
Partamos aqui da proposição tractariana, a de número 4.022, visto ela introduzir tanto a noção de mostrar, apresentar ou exibir (zeigen), como seu contrário dizer (sagen).

Esta é uma distinção que assumirá, ao longo do "Tractatus", uma relevância cada vez maior. Esta distinção, de certa maneira, divide toda a linguagem em dois campos (segmentos e que correspondem realmente a dois mundos).

Em 4.022 podemos notar que a proposição em pauta mostra o seu sentido original, ao mesmo tempo em que a proposição 4.1112 vem completá-la dizendo: "O que pode ser mostrado (gezeigt) não pode ser dito (gesagt)".

O grau daquilo por nós destacado acima se refere à relação entre aquilo que pode ser dito pela proposição, isto é pela linguagem, e que, portanto pode ser pensado, e aquilo que por ela não pode ser expresso, mas apenas pode ser mostrado, e que expressa o problema fundamental da filosofia para Wittgenstein.

Ainda em 4.022 diz Wittgenstein: "A proposição mostra, se for verdadeiro, como estão as coisas. E diz que isto está assim."

Isto reitera o ponto de vista wittgensteiniano segundo o qual só a proposição diz propriamente, à medida que ela representa ou figura o real. Mas, ao mesmo tempo, a proposição mostra algo. Vale dizer: ela mostra o seu próprio sentido.

Em 2.221 é dito: "A figuração concorda ou não com a realidade, é correta ou incorreta, verdadeira ou falsa".

Ao mesmo tempo em que a proposição mostra o sentido, está excluída dela a possibilidade de dizer aquilo que pode ser mostrado. Em 4.1212, diz-se ainda: "o que pode ser mostrado, não pode ser dito".

O que tudo aqui está implicado é a impossibilidade de representar a forma lógica.

Isto é arrematado na proposição:

4.12: “A proposição pode representar a realidade inteira, não pode, porém, representar o que ela deve ter em comum com a realidade de poder representá-la - a forma lógica".

"Para podermos representar a forma lógica seria preciso nos colocar, com a proposição, fora da lógica, a saber, fora do mundo". 
Isto vale a dizer que a figuração ou forma de representação só pode ser mostrada, exibida, jamais dita.

Mas de que impossibilidade realmente se trata? Embora a proposição possa figurar toda a realidade - real ou possível não se pode fazê-lo com relação à forma lógica, a forma da representação, pois para tal se torna necessário que ela mesma se colocasse ou fora da sua própria forma de representação. Aqui se faz presente a questão relativa à impossibilidade de uma metalinguagem, que já fora exposta em 2.174 que "a figuração não pode, porém, colocar-se fora de sua forma de representação".

Para que a proposição, enquanto figuração, pudesse figurar a sua própria forma lógica, seria necessário que ela pudesse usar outra figuração que não a sua própia, sua forma original, o que é uma impossibilidade.

À medida que a forma lógica não é uma possível combinação de objetos, um possível "estado de coisas", não pode, portanto ser figurado, já que pela definição a figura só pode figurar de coisas, combinação de objetos.

A possibilidade da forma de figuração venha ser figurada por outra figura de ordem ou nível superior redunda numa impossibilidade, o que delimita para Wittgenstein as tentativas feitas por Russel (Teoria dos Tipos) e e outros, de construir uma metalinguagem ou série de metalinguagens. Isto terminaria por se fechar num regresso ao infinito.

Isto não significa que a forma da figuração não possa ser captada por nós, indica antes a possibilidade de ser captada na sua forma de representação, sem que isto implique fazê-lo sem o modo de "figurar" ou "dizer". Antes ela, a figura "mostra" a sua forma de figuração. Isto se explicita na proposição:

(4.121): “A proposição não pode representar a forma lógica, esta espelha-se naquela"

"Não é possível representar o que se espelha na linguagem".

O que deu origem esta entre dizer e mostrar? Ela está necessariamente ligada à concepção da linguagem, da proposição - figuração imediata, pictórica, enquanto uma espécie de retrato da realidade empírica, do estado de coisas. 
Aqui nos deparamos, mais uma vez,com a relevância dos pressupostos da teoria isomórfica da linguagem de Wittgenstein, que tudo fundamenta. Daí deriva-se as concepção segundo a qual, tanto a lógica quanto a matemática, a filosofia e a estrutura a priori da linguagem, não podem ser ditos, mas tão somente mostrados.

\section{Dizer e Mostrar: especificações}

Expliquemos melhor as questões lógico-filosóficas acarretadas pela relação entre: dizer e mostrar. Vem-nos à mente aqui, num primeiro momento, a distinção kantiana entre conhecer e pensar.

A possibilidade de um fato que seja pelo menos possível de ser representado ou descrito pela proposição elementar.

4.022 “A proposição mostra seu sentido. proposição mostra, se for verdadeiro, como algo está. E diz isto está assim"

Neste sentido, a proposição, à medida que é um fato como outros, representa ou expõe os elementos ao mesmo tempo em que diz algo para, além disso, diz algo. A preposição diz um fato, à medida que só é possível dizer fatos ou um fato, e o fáz através dos objetos. Este agenciamento se faz através de uma figuração que comporta uma forma lógica que tem como representante o fato ou estados de coisas, enquanto só as proposições dizem, ao mesmo tempo que os nomes podem somente nomear. A proposição enquanto agenciamento de um fato ou representação deste ou dos estados de coisas mostra-os, sem que possa dizê-los. Este mostrar da proposição expõe o que há de comum entre o fato descrito, ou seja, uma estrutura que é comum a ela e ao fato descrito. Isto indica a dupla estrutura da linguagem, que remete à negação da metalinguagem por Wittgenstein. À medida que a proposição diz um fato, ela mostra outro, que é resultado do fato de dizer. Está em jogo aqui a impossibilidade para Wittgenstein de certas relações semânticas entre a proposição e a figuração.

Se assim é, isto se deve a que a proposição pode dizer alguma algo, que ela remete a algo mais, mais que um fato ou um signo. 
3.1 "Na proposição o pensamento se exprime sensível e perceptivelmente."

3.2 "Chamo signo proposicional o signo pelo qual exprimimos o pensamento. E a proposição é o signo proposicional em sua relação projetiva com o mundo".

Desta forma é o pensamento que estabelece na relação projetiva com o mundo é aquele momento e este é visado por ela.

3.11 "Utilizamos o signo sensível e perceptível (signo sonoro ou escrito, etc.) a proposição como projeção da situação possível.

O método de projeção é o pensar do sentido da proposição."

3.5 "O signo proposicional empregado e pensado é o pensamento".

4. O pensamento é a proposição significativa”

Estabelece-se aqui uma dupla relação entre a proposição e o pensamento, ao mesmo tempo em que uma diferença entre a proposição e o signo proposicional, enquanto este é apenas uma "expressão sensível do pensamento". O pensamento aparece aqui enquanto conteúdo conceitual e ainda não afirmado e que, ao mesmo tempo objetivo e independente, no nosso próprio espírito. Aqui o signo proposicional tem por função exprimi-lo.

No prefácio do Tractatus Wittgenstein diz que: "Pretende, por tanto estabelecer um limite ao pensar, ou melhor, não ao pensar mas à expressão do pensamento, portanto para traçar um limite ao pensar deveríamos poder pensar ambos os lados desse limite (de sorte que deveríamos pensar o que não pode ser pensado)".

O limite será pois, traçado unicamente no interior da língua, tudo o que fica além dele será simplesmente absurdo.

Parece que a distinção entre "dizer e mostrar" aponta para o aprofundamento e a solução deste problema. Aqui ainda estão situados a problemática do místico, do expremível, o pensamento pela proposição, e o mostrável pelos signos que na proposição estão pelos nomes e, por sua vez pelos objetos ou estados de coisas.

Problemata: R. Intern. Fil. v. 5. n. 1 (2014), p. 64-93

ISSN 2236-8612 
O limite da linguagem mostra-se na impossibilidade de descrever os fatos, o qual corresponde a uma proposição. (Temos aqui operar com a solução kantiana do problema da filosofia). ${ }^{1}$

Os problemas dos limites do pensamento em Wittgenstein remete às questões da ética e do místico. Para ele a ultrapassagem do pensamento além de seus limites é algo de não ético e indica uma impossibilidade. Já no Prefácio do Tractatus, enfatiza Wittgenstein a relação entre estes limites da linguagem e o sem-sentido da ultrapassagem destes limites, "olimite será, pois traçado unicamente no interior da língua; tudo que fica além dele será simplesmente absurdo." (Unsinn). Prefácio.

Em contraposição a este limite imposto pela linguagem e possibilidade de produção do sentido e do sem-sentido ou absurdo, é a fronteira que vai permitir estabelecer no Tractatus aquilo que podemos dizer enquanto algo sensato, aquilo que pode ser dito: os fatos, a positividade, o mundo e sua presença na linguagem.

Identificar pensamento com a proposição, enquanto uma é imagem, é identificá-las na identidade da "forma lógica", que é, ao mesmo tempo, a "imagem lógica" de um fato diz em:

2.182 que "toda figuração também é lógica. (No entanto, nem toda figuração é, por exemplo, espacial)".

2.2 "A figuração tem em comum com o mundo afigurado a forma lógica da afiguração".

Somente o pensamento afigurado o mundo enquanto sua imagem/figura lógica, enquanto constituído de fatos, sendo assim a figuração é a imagem lógica de um fato. Tudo aquilo que é passível de ser representado ou figurado, ou estar por alguma coisa é sua figuração de uma maneira lógica, embora existam outras maneiras de figurar (espacialmente, temporalmente, etc.). Deste modo a figuração permite dizer-se ou pensar-se aquilo que é pensável ou dizível enquanto estados de coisas que podem figurar e aqui aparecer algo de comum a todas as figurações que é a forma lógica:

Diz 2.182 "O que cada figuração, de forma qualquer, deve sempre ter em comum com a realidade para poder afigurá-la em geral - correta ou falsamente - é a forma lógica, isto é, a forma da realidade". 
Aqui o lógico ou a logicidade aparece como aquilo que há de comum a todas as figuras dos fatos e quanto remetem ao pensamento ou proposição como sua imagem, temos tão somente uma figura puramente lógica. Noutras palavras: a proposição figura a lógica, o mundo. Há assim uma identidade, uma estrutura comum, entre a figura e o fato que ela representa ou figura, o que permite que a figura possa representar, estar por um fato: está é a "forma figurativa (Form der Abbildung). Por fim, a forma lógica pode ser dita a "fora da realidade", ou da factualidade.

\begin{abstract}
No que diz respeito à proposição, a forma da afiguração ou forma figurativa, é idêntica ou coincide com a forma lógica, o garante a capacidade de representar enquanto imagem. Diz "2.11 - A figuração presenta a situação no espaço lógico, a subsistência de estados de coisas".
\end{abstract}

Aqui a proposição é dita ter um sentido que é anterior a qualquer confronto com a experiência, algo que é portanto anterior ao estabelecimento do seu valor de verdade e antes de ser formulada ou não.

Portanto ter um sentido significa apresentar um estado de coisas, à medida em que o afigura, enquanto uma possibilidade, que se inscreve no espaço lógico. Di:z 2.12 "A figuração é um modelo da realidade."

Enquanto a imagem é um modelo de realidade, vale dizer, uma figuração da realidade através de um fragmento, espécie de uma miniatura que é tomada da própria realidade.

$\mathrm{Na}$ figura encontramos coordenados aqueles elementos entre o fato e aquilo que o representam. Encontramos assim um isomorfismo entre o real e o fato representado através da imagem. Põe-se uma relação de termo-a-termo que abstrai-se do conteúdo empírico imediato e que vem a ser o pensamento de uma parte do mundo, ou uma proposição.

Diz : 2.14 "A figuração consiste em que seus elementos estão uns em relação aos outros de um modo determinado".

Diz: 2.17 "Deve haver algo de idêntico na figuração e no afigurado a fim de que possa ser a figuração do outro". 
Neste sentido a imagem é uma fixação da posição do fato entre possíveis, mostra-lhe o seu lugar ou o lugar a ocupar no espaço lógico, o que se dá antes mesmo de qualquer enfrentamento com os dados empíricos.

Diz-se 4.01 - A proposição é a figuração da realidade.

"A proposição é o modelo da realidade tal como a pensamos".

Aqui a imagem mostra imediatamente seu sentido, à medida em que é plena de sentido (sinnvoll): o sentido é mostrado pela figuração de uma situação possível no espaço lógico. Ao exprimirmos um pensamento ou proposição, ao fazêlo, ao mesmo tempo, mostramos o seu sentido pela apresentação de uma posição possível, o que quer dizer o mesmo. Neste sentido a proposição mostra "a priori" seu sentido, sem que tenhamos ainda qualquer referência à realidade concreta, e que não implica ainda a noção de que ela seja verdadeira ou falsa, permita que possamos compreender frases jamais ouvidas, sem que tenham explicado seu sentido. $\mathrm{O}$ sentido da proposição já está ali, ele é e está "a priori" sem que ainda tenha sido referida à realidade empítica, ele é sua condição de possibilidade. O fato de que se possa partir da proposição, indica a possibilidade de construção do mundo através do aparelho lógico e que possa ser assim que as coisas se dão para tudo aquilo que é lógico, caso seja ela verdadeira. Da falsidade de uma proposição pode-se inferir conclusões. Aquilo que é "a priori" que é no caso que ela seja verdadeira. A proposição tem um estatuto de uma "norma de referência em relação à qual os fatos de dispõem". A proposição apresenta o possível, mostra o possível e diz que esse possível é (seja verdadeiro ou falso). A linguagem tem possibilidade de representar todo o real e tão somente o real, não podendo portanto dizer o que ultrapassa o real, aquilo que é impensável ou indizível. É possível para a proposição dotada de sentido representar um fato impossível no espaço lógico.

Diz 3.02 - "O pensamento contém a possibilidade da situação que pensa. O que é pensável também é possível."

A possibilidade de um fato vem mostrar o lugar lógico do espaço que é expressa a proposição com sentido. 


\section{A Filosofia}

A solução da pergunta filosófica não deve jamais surpreender. Não se pode descobrir nada na filosofia.

4.111 - A filosofia não é a ciência da natureza (A palavra filosofia deve denotar alguma coisa que se coloca acima ou abaixo mas não ao lado das ciências naturais).

A filosofia não tem nada a dizer: é uma atividade ( não uma teoria) dirigida para clarificação dos pensamentos.

Esta reflexão de Wittgenstein sobre a filosofia é a conseqüência direta do problema que procura resolver com a distinção entre aquilo que pode ser dito e aquilo que pode ser mostrado.

Isto implica ainda, segundo expressa 6.53 que a "ciência" consiste naquilo que pode ser dito.

Mas podemos perguntar, se, à medida que a filosofia não nos fala a verdade, de que fala ela? A resposta está em::

4.112 “A finalidade da filosofia é o esclarecimento lógico dos pensamentos, A filosofia não é teoria mas atividade.

Uma obra filosófica não resulta em "proposições filosóficas" mas em tornar claras as proposições".

A filosofia deve tornar os pensamentos que, por assim dizer, são vagos e obscuros e torná-los claros e bem delimitados.

A base da filosofia está a lógica e a metafísica. Ela não possui caráter dedutivo, mas tem uma natureza antes descritiva, ela está proibida fazer qualquer dedução.

$\mathrm{Na}$ "Investigações Filosóficas" diz Wittgenstein sobre o tema:

"Toda explicação tem que desaparecer e só a descrição haverá de ocupar seu lugar. E esta descrição recebe sua luz, isto é, sua finalidade, dos problemas filosóficos. Estes não são certamente empíricos, mas que se resolvem mediante uma olhada no funcionamento de nossa linguagem, e justamente de maneira que esta se reconheça: apesar de uma inclinação a mal entendê-la. 
Os problemas se resolvem não aduzindo novas experiências, mas compilando o já conhecido. A filosofia é uma luta contra o enfeitiçamento de nosso entendimento por meio da linguagem" ${ }^{2}$

4.113 - "A filosofia delimita o domínio contestável das ciências".

4.114 - "Deve delimitar o pensável e com isso o impensável”.

Já no prefácio ao "Tractatus" Wittgenstein procurou a finalidade do livro. Trata-se de delimitar os limites entre o pensável e aquilo que não pode ser pensado; entre o que se pode dizer (pensar) e que somente pode ser mostrado. E isto só pode ser feito por meio do estudo filosófico de nossa linguagem. A tarefa da filosofia se limita assim a análise de linguagem e sua estrutura lógica. Mostrando a lógica de nossa linguagem, pudesse estabelecer com precisão os limites entre o dizível e o indizível.

6.53 - "Método correto em filosofia seria propriamente: nada dizer a não ser o que pode ser dito, isto é, proposições nada tem a haver com a filosofia; e sempre que alguém quisesse dizer algo a respeito da metafísica, demonstrar-lhe que não conferiu denotação a certos signos de suas proposições. Para outrem esse método não seria satisfatório - ele não teria o sentimento de que lhe estaríamos ensinando filosofia - mas seria o único método estritamente correto."

Através das tentativas da clarificação da lógica da linguagem a filosofia mas não se transforma nem vem a ser uma ciência; mas ela contribui com isso para indicar os limites entre a ciência e sobretudo o que se pode opinar, pensar ou dizer;

4.114 - "Deve delimitar o pensável e com isso o impensável.

Deve demarcar o impensável do interior por meio do pensável."

Apresenta-se deste modo a função negativa da filosofia, ou seja: procura separar as proposições dotadas de sentido daquelas que não o são, como as proposições metafísicas. Vale 
dizer, encará-las segundo as possibilidades de que possam ser verdadeiras ou falsas. Do contrário elas são indecidíveis, e fica assim fora da tarefa da filosofia delas tratar. As proposições possíveis de serem pensadas, podem sê-los de forma clara, e, à medida em que assim o são, podem ser expressas pela linguagem, portanto pela lógica.

4.116 - "Tudo em geral que pode ser pensado o pode claramente. Tudo o que se deixa exprimir, deixa-se claramente

4.12 - “A proposição pode representar a realidade inteira, não pode, porém, representar o que ela deve ter em comum com a realidade para poder representá-la a forma lógica.

Para podermos representar a forma lógica seria preciso nos colocarmos com a proposição, fora da lógica, a saber fora do mundo."

4.121 - proposição não pode representar a forma lógica, esta espelha-se naquela.

Não é possível representar o que se espelha na linguagem.

O que se exprime na linguagem não podemos expressar por meio dela.

A proposição mostra a forma lógica da realidade.

Ela a exibe".

4.1212 - O que "pode" ser mostrado "não pode" ser dito.

Como elemento mediador entre a linguagem e o mundo encontramos a forma lógica, o que permite que a linguagem fale sobre o mundo. Pela relação entre linguagem e mundo através da forma lógica, pode-se estabelecer uma relação entre proposição e fato. É também a forma lógica que permite relacionar os vínculos entre a figuração lingüística do mundo e aquilo que a figuração tem em comum com o figurado. $\mathrm{Na}$ forma lógica enquanto se dá uma identidade isomórfica entre a linguagem e mundo. Isto permite à linguagem descrever os fatos 
e esta é sua razão de ser. Este é o elemento fundamental da teoria figurativa da proposição.

2.18 - O que cada figuração de forma qualquer, deve sempre ter em comum com a realidade para poder afigurá-la em geral - correta ou falsamente - é a forma lógica, isto é, a forma da realidade".

É a forma lógica que dá à proposição seu sentido. E assim dá a esta seu caráter descritivo. Enquanto possível de dizer algo, a proposição só pode fazê-lo enquanto compartilha a forma lógica daquilo que diz. Tanto quanto o sentido, a forma lógica não pode ser expressada mas somente mostrada. A proposição não pode dizer qualquer coisa sobre si mesma. Aquilo que pode ser dito só pode ser feito em proposições e estas figuram sempre algo que lhe é estranho. Se não fosse assim ela não teria possibilidade de ser falsa.

No Prefácio esta relação entre o "dizer e o mostrar" foi melhor precisada e identificada. Ao pensamento mesmo não se pode por limites, e assim poder-se-ia poder pensar o impensável. A atividade filosófica deve se limitar ao âmbito, ao domínio das "expressões", do pensamento, e também sobre o que se pode dizer e o mostrar será traçado unicamente no interior da linguagem; tudo que fica para além dela será simplesmente absurdo. Será o indizível, sem sentido (unsinn), o que não quer dizer que seja sem significado (sinnlos). proposição.

Pois aquilo que não pode ser dito, pode ser mostrado na

É exatamente aqui que se faz valer o apelo à linguagem como o limite, tanto negativo quanto positivo, que se estabelece entre o exprimível, dizível, que para além dele não é possível qualquer ponte, mas que aponta como uma seta, para o sentido, que é aquilo que é mostrado. Na forma lógica da proposição ou na sua figuração na forma lógica.

Trata-se portanto de procurar nos limites da linguagem, por meio da análise da sua forma lógica, aquilo que nas palavras do próprio Wittgenstein no Prefácio se deixa transparecer:

"Poder-se-ia apanhar todo o sentido do livro com estas palavras: em geral o que pode ser dito, o que pode ser claramente, mas o que não se pode falar deve-se calar". 
Mais ainda trata-se de estabelecer as relações de sentido entre o pensamento e aquilo que é sua expressão na forma da linguagem, à medida em que esta é uma figuração sígnica e simbólica daquele. A lógica cabe descobrir-se como aquilo que mostra na linguagem, nos signos que representam a sua forma, sua expressão da forma do mundo, à medida em que há uma relação de implicação direta entre linguagem, lógica e mundo.

O trabalho da filosofia, sua tarefa é portanto a crítica. Assim como Kant que pretendeu apresentar os limites do conhecimento humano, Wittgenstein buscou por meio de suas investigações lógico-linguísticas tornar significativas os limites da fala com sentido ou cheia de sentido.

Mas diferentemente de Kant as investigações de Wittgenstein terminam no místico e no silêncio.

A primeira frase do Prefácio do Tractatus dão muito no que pensar.

“Talvez este livro seja compreendido por quem já tenha cogitado por si próprio os pensamentos aqui expressos, ou ao menos cogitado pensamentos semelhantes".

Poder-se-ia perguntar pelas conseqüências da tarefa de Wittgenstein, procurando estabelecer os limites entre as implicações metafísicas do seu trabalho e as suas investigações lógicas. Qual delas pode-se dizer que é a prevalecente: o silêncio ou mostrar-se/dizer?

\section{O Mundo}

1. O mundo é tudo que ocorre.

E tudo que ocorre, ocorre no espaço lógico.

1.2- O mundos e resolve em fatos.

1.21 - Algo pode ocorrer e não ocorrer e todo o resto permanecer na mesma.

1.13 - Os fatos no espaço lógico são o mundo. 2.063 - A realidade inteira é o mundo. 
2.06 - A subsistência e a não subsistência dos estados de coisas é a realidade.

2.01 - O estado das coisas é uma ligação de objetos (coisas - a ligação de objetos (coisas).

O que são estados de coisas podemos imediatamente compreender se tivermos previamente compreendido o conceito de proposição elementar, diferentemente da proposição em geral.

4.211 - É o signo da proposição elementar que nenhuma outra pessoa possa estar em contradição com ela.

4.22 - A proposição elementar é constituída de nomes. É uma conexão, um encadeamento de nomes.

E o nome está pelos objetos. Representa-os.

4.23 - O nome só aparece na proposição em conexão com as proposições elementares.

elementares são:

Os nomes os quais aparecem nas proposições

3.26 - O nome não é para ser desmembrado ademais por uma definição:

$\mathrm{O}$ que não permite qualquer definição ou qualquer recurso à meta-linguagem que possa falar dos nomes. Já que eles são signos primitivos.

3.262 - O que no signo não vem expresso é indicado pela aplicação.

O que os signos escondem, aplicação exprime.

3.263 - As denotações dos signos primitivos podem ser esclarecidas por elucidações. Elucidações são proposições que contém os signos primitivos. Só podem portanto ser entendidas quando já se conhece as denotações desses signos.

3.203 - O nome denota o objeto. O objeto é sua denotação ("A" é o mesmo signo que "A").

3.3 - Só a proposição possui sentido; só em conexão com a proposição, um nome tem denotação.

Problemata: R. Intern. Fil. v. 5. n. 1 (2014), p. 64-93

ISSN 2236-8612 
3.363 - As denotações dos signos primitivos podem ser esclarecidas por elucidações. Elucidações são proposições que contém os signos primitivos. Só podem portanto ser entendidas quando já se conhece as denotações desses signos.

Os elementos últimos da proposição são aqueles signos simples aos quais chegamos quando a tivermos analisado de todo.

E para Wittgenstein estes signos são nomes. Basta para tal que leia-se Proposição 3.203 citada acima. Isto segue a teoria isomórfica da linguagem, no que se refere à questão da representação na relação entre os nomes e os objetos. As proposições podem ser decompostas em nomes, já que seus elementos ou signos mais simples são simplesmente nomes, e suas referências são os objetos a que cada um se refere.

Aos nomes da proposição correspondem os objetos do fato representado. Ao mesmo tempo correspondem à figuração ou agenciamento na proposição que correspondem à figuração dos objetos no fato. Daí se segue a única maneira de falar dos objetos seja nomeando-os. Já no que se refere aos fatos ou situações não podem ser nomeados, mas tão somente descritos. Descrever quer dizer que a estrutura que representa o fato por meio da estrutura isomórfica da proposição.

Esta estrutura é o sentido (Sinn) da proposição. Já no que se refere a nomear e colocar um signo simples enquanto representa um objeto.

Nesse sentido um signo é um nome somente quando funciona enquanto tal no contexto proposicional. Daí a afirmação de Wittgenstein em:

3.3 - Só a proposição possui sentido; só em conexão com a proposição, um nome tem denotação.

Para Wittgenstein um nome, se de fato é um nome em sentido lógico, se limita a nomear, de tal modo que não pode ter sentido, pois do contrário poderia ser utilizado para descrever o objeto, o que implicaria que não seria um signo simples, mas antes teria alguma complexidade. Contrariamente ao nome, a proposição tem sentido que é o fato que ela representa, mas não 
pode ser referência, já que ela não é o nome de coisa alguma. $\mathrm{O}$ sentido da proposição é saber se aquilo que ela representa é o caso, é o seu valor de verdade que é a expressão de que o representado por ela existe ou não existe.

Os intérpretes de Wittgenstein parecem unânimes em dizer que a relação dos nomes com os objetos e suas respectivas conexões na realidade permanecem algo de obscuro.

No entanto, Wittgenstein diz que os nomes podem ser decompostos posteriormente por meio de uma definição, dado que são signos simples e primitivos, (cf. 3.26). Agora, o que se expressa no nome, ou seja, sua conexão com o objeto, se mostra pela sua aplicação, daí a possibilidade de que a denotação dos nomes, ou signos primitivos, possa ser explicada através de esclarecimentos, ou por meio de proposições que contenham tais signos (3.263). O uso de tais signos permitirá mostrar a que se refere os nomes que nelas surgem. No entanto elas só podem ser entendidas se se conhece a denotação de seus signos. Isto pode ser explicado, sem que caia num círculo vicioso, à medida o uso da linguagem pressupõe a conexão entre seus signos simples e os objetos do mundo. À medida que se ensina como se usa a linguagem, esta conexão pode ser mostrada, embora não possa ser explicada.

Uma proposição não é mais do que uma representação figurativa da realidade, um modelo da realidade tal como e como a concebemos.

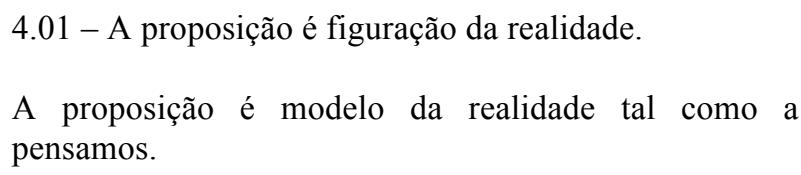

Wittgenstein dirá que o disco fonográfico, o pensamento musical, a partitura e as ondas sonoras se encontra entre si numa relação interna de representação, do mesmo modo como a que existe entre a linguagem e o mundo; todas estas coisas têm uma estrutura comum.

4.014 - O disco da vitrola, o pensamento e a escrita musicais, as ondas sonoras estão uns em relação aos outros no mesmo relacionamento existente entre a linguagem e o mundo.

A todos é comum a construção lógica. 
Assim entre a linguagem e o pensamento e a realidade existe uma correlação de estruturas. Há uma lei de projeção que permite projetar essas coisas em termos da outra.

4.0141 - Que exista uma regra geral por meio da qual o músico possa surpreender a sinfonia a partir da partitura, regra por meio da qual se possa derivar a sinfonia das linhas do disco e ainda, segundo a primeira regra, de novo derivar a partitura, nisto consiste propriamente a semelhança interna dessas figuras aparentemente tão diversas. E essa regra é a linguagem musical. É a regra da tradução para a linguagem do disco.

A proposição é a descrição de um estado de coisas ou situação. Para Wittgenstein e de acordo com sua teoria da representação, as proposições se caracterizam pelo fato de seu sentido ser prévio a sua verdade ou falsidade, daí ser possível que uma proposição possa ser entendida sem que se saiba se ela é verdadeira ou falsa.

4.022 - A proposição "mostra” seu sentido.

A proposição "mostra", "se" for verdade como algo está.

E diz que isto "está" assim.

4.031 - Uma situação é justaposta à proposição, por assim dizer, por tentativas".

É possível dizer diretamente: esta proposição representa esta ou aquela situação, em vez de esta proposição tem este ou aquele sentido.

Isto implica saber se os fatos serão dessa maneira caso a proposição seja verdadeira. Se de fato compreendemos uma proposição, e antes de sabermos se ela é verdadeira ou falsa, podemos apreender uma possibilidade. Neste sentido, para Wittgenstein, a proposição enquanto uma representação, e isto vale para a representação em geral, determina um lugar no espaço lógico, a possibilidade da existência da situação que ela representa, dado que o lugar lógico coincide com o lugar geométrico em que ambos são a possibilidade de uma existência.

Problemata: R. Intern. Fil. v. 5. n. 1 (2014), p. 64-93 
3.4 - “A proposição determina um lugar no espaço lógico. A existência desse espaço lógico é assegurada pela existência das partes constitutivas, pela existência das proposições significativas".

3.411 - "O lugar geométrico e o lógico concordam em ambos consistem na possibilidade de uma existência."

O que é representado por uma proposição é, por conseguinte, uma situação ou um estado de coisas possíveis. E isto se dá na proposição por intermédio da figuração dos nomes dos quais ela se compõe.

Assim podemos compreender quando Wittgenstein diz que entendemos uma proposição bastando que seu sentido seja mostrado nela, não necessitando-se qualquer explicação ulterior.

4.021 - "A proposição é figuração da realidade; pois conheço a situação representada por ela quando entendo a proposição. E entendo que se mostra neste caso é sua estrutura”.

No entanto:

4.026 - “As denotações dos signos simples (das palavras) nos devem ser explicadas para que as compreendamos".

Com as proposições compreendemos a nós mesmo.

Aqui o que se precisa é que seja explicado a referência dos constituintes ou seja de seus nomes, uma vez que é uma relação entre eles e a realidade, entre eles e os elementos menos complexos da realidade. Neste sentido é necessário à proposição que ela possa comunicar um novo sentido através de velhas expressões, já que com os mesmos nomes podemos formar diferentes sentidos, o que vale dizer, diferentes proposições, segundo combinações de diferentes estruturas os nomes de diferentes modos.

4.027 - "Está na essência da proposição poder comunicar-nos um "novo" sentido".

4.0311 - "Um nome presenta uma coisa, outro, outra coisa, e estão ligados entre si de tal modo eu o todo como quadro vivo (Eilebendes Bild) - presenta o estado de coisas". 
A possibilidade de decomposição da linguagem em nomes é conseqüência do princípio isomórfico com o mundo que ela comporta. Aos nomes cabem permitir à linguagem que ela possa "tocar" a realidade, à medida em que ela pode ser decomposta, a linguagem como figuração, ela pode ser submetida à análise lógica, permitindo assim que se possa estabelecer aquelas partes que nela possa distinguir as partes que representam as situações.

4.0312 - A possibilidade da proposição se estriba no princípio da substituição dos objetos por meio de signos.

Meu pensamento basilar é que as "constantes lógicas" nada substituem; e a "lógica dos fatos não se deixa substituir.

4.04 - Tanto se distinguirá na proposição quanto na situação que ela representa.

Ambos devem possuir a mesma multiplicidade lógica( matemática).

(Cf. a mecânica de Hertz a propósito dos modelos dinâmicos)

Daí não se conclue que as diferentes partes da linguagem se dêm gramaticalmente separadas. O que aqui é pressuposto é uma análise lógica. É neste sentido que pode compreender o que diz Wittgenstein na proposição 4.032 -



(Também a proposição Ambulo é composta, pois sua raiz com outra desinência nos dá outro sentido, o mesmo acontecendo se está desinência estiver com outra raiz).

O princípio segundo o qual o sentido de uma proposição é sua estrutura e que representa uma situação ou estado de coisas possíveis, não implica que para que uma proposição seja tal, no caso uma figura, precise que exista a situação representada. Isto só se faz necessário no caso de que a proposição seja verdadeira.

Problemata: R. Intern. Fil. v. 5. n. 1 (2014), p. 64-93

ISSN 2236-8612 
4.1 - “A proposição representa a subsistência e não subsistência dos estados de coisas".

Porém à medida em que a proposição representa a não existência de um estado de coisas, ela deve estar negada. Neste caso a negação se acrescenta complexa e logicamente à própria estrutura figurativa de um estado de cosias.

2.06 - A subsistência e não subsistência dos estados de coisas é a realidade.

(Chamamos de fato positivo à subsistência de estados de coisas e de negativo à não subsistência deles). O que aqui se expressa é que uma proposição negativa não possa corresponder a nenhum fato de caráter negativo, um fato negativo é tão somente um fato inexistente. As proposições elementares são aquelas que afirmam a existência de um estado de coisas, razão pela qual duas proposições elementares não podem ser com relação a outra contraditória, pois só poderiam ser assim caso uma delas fosse negativa, e em tal caso não seria elementar.

4.211 - "É um signo da proposição elementar que nenhuma outra possa estar em contradição com ela."

Do mesmo modo não se pode deduzir uma proposição elementar de outra, o que só é possível se, pelo menos, uma delas é complexa. No que tange às proposições elementares, à lógica cabe dizer tão somente que elas devem existir. Apresentada a linguagem, aí se apresenta o fundamento "a priori” das proposições elementares. Segundo o princípio de extensionalidade, exige-se logicamente que as proposições complexas sejam funções-verdade de proposições das proposições elementares.

5.5562 - Por motivos puramente lógicos sabemos que deve haver proposições elementares: desse modo, isto deve ser conhecido por todo aquele que compreende as proposições na sua forma não analisada.

No entanto não cabe à lógica dizer que proposições elementares existem, o que comportam elas e quais são suas formas. Procurar explicar tais questões aprioristicamente rendudará no sem-sentido. 
5.55 - Devemos agora "a priori” responder à pergunta a respeito de todas as formas possíveis de proposição elementares.

A proposição elementar constitui-se de nomes. Posto que não podemos dar o número de nomes com denotação diferente, não podemos também dar a composição das proposições elementares.

5.5571 - Se não posso indicar "a priori” as proposições elementares, querer indicá-las deve redundar num patente absurdo (unsinn).

Aqui se coloca um problema empírico. Lembremos que para obtermos a totalidade das proposições elementares necessitar-se-ia ter disposição a totalidade dos objetos aos quais elas se referem, o que termina por ser uma questão empírica que se atém ao nosso conhecimento crescente do mundo.

Aquilo que se possa decidir sobre as proposições elementares quanto a sua existência, quantas existem, só pode ser decidido pela aplicação da lógica e que não pode ser antecipado pela própria lógica.

5.557 - A "aplicação da lógica decide que proposições elementares existem.

O que está na aplicação a lógica não pode antecipar.

É claro: a lógica não há de colidir com sua aplicação.

Mas a lógica deve referir-se à sua aplicação.

Desse modo, a lógica e sua aplicação não devem sobrepor-se uma à outra.

Necessita-se, para aplicação da lógica à medida em que se refere ao nosso conhecimento do mundo, de componentes empíricos estranhos à própria lógica. Recorrer aos nomes se faz necessário para dar as formas das proposições elementares e para tal temos que conhecer de alguma maneira seus referentes, remetendo-se assim ao que há no mundo. No entanto na lógica não podemos decidir que exista isso ou não aquilo no mundo. 
5.61 - A lógica preenche o mundo, os limites do mundão são também seus limites.

Não podemos pois dizer na lógica: isto e isto existem no mundo, aquilo não.

Portanto se pressuporia aparentemente que excluímos certas possibilidades, o que não pode ocorrer pois, do contrário, a lógica deveria colocar-se além dos limites do mundo, como se pudesse considerar esses limites também do outro lado.

Não podemos pensar o que não podemos pensar, por isso também não podemos dizer o que não podemos pensar.

Ao lógico, não cabe dar exemplos.

$\mathrm{O}$ princípio de isomorfia só cabe ser aplicado às proposições elementares. Quanto as proposições complexas, estas conteriam, além de nomes aqueles elementos que não encontram correspondência na realidade, tais como quantificadores e diferentes partículas conectivas. Pela análise das proposições complexas chegamos diretamente a proposição simples. E este é o suposto do atomismo lógico de Wittgenstein. Os nomes estão concatenados na proposição simples. Os símbolos são funções de nomes.

4.221 - É óbvio que, graças à análise da proposição, devemos chegar a proposições elementares que consistam de nomes numa vinculação imediata.

Pergunta-se aqui como se dá o vínculo proposicional.

4.22 - A proposição elementar é constituída de nomes. É uma conexão, um encadeamento de nomes.

4.24 - Os nomes são símbolos mais simples, indico-os por letras singulares (“x”, “y”, “z”).

Escrevo as proposições elementares como função dos nomes, com a seguinte forma: " $f \mathbf{x} ", \emptyset(\mathbf{x}, \mathbf{y})$, etc. ou indico-as por meio de letras $\mathbf{p}, \mathbf{q}, \mathbf{r}$.

Aqui está tudo que a lógica pode nos ensinar sobre a linguagem. Trata-se de saber o que nos mostra a linguagem sobre o mundo. 


\section{Análise e Figuração}

A filosofia enquanto atividade para Wittgenstein é ao mesmo tempo crítica: acontece na distinção entre sentido e semsentido, nos limites entre ele, do que pode ser dito, e o que propriamente não pode ser dito.

4.022 - O homem possui a capacidade de construir linguagens nas quais cada sentido se deixa exprimir, sem contudo pressentir como e o que cada palavra denota. Assim se fala sem saber como os sons singulares são produzidos.

A linguagem corrente forma parte do organismo humana e não é menos complicada do que ele.

É humanamente impossível de imediato aprender dela a lógica da linguagem.

A linguagem veda o pensamento, do mesmo modo, não é possivel concluir, da forma exterior da veste, a forma do pensamento vestido por ela; Porquanto a forma exterior da veste não foi feita com intuito de deixar conhecer a forma do corpo. Os acordos silenciosos para entender a linguagem corrente são enormemente complicados.

$\mathrm{Na}$ lógica da linguagem na qual é lida imediatamente a humana possibilidade, chegar a esclarecer o seu funcionamento e um entendimento de sua função de mostrar deve ser feita pelo homem na própria linguagem.

3.325- "Para evitar erros devemos usar uma linguagem simbólica que os exclua, pois está não empregará significativamente o mesmo signo para símbolos diferentes, e não empregará signos, que designam do mesmo modo. Uma linguagem simbólica, portanto, que obedece a gramática "lógica" - à sintaxe lógica".

Quando há sentido, nós pensamos e aí figuramos proposições que se deixam aparecer em expressões. Proposições chama-se no Tractatus figurações da realidade. O pensamento constitui-se o tema central do Tractatus e Wittgenstein procura traçar os limites do pensamento através da expressão na

Problemata: R. Intern. Fil. v. 5. n. 1 (2014), p. 64-93

ISSN 2236-8612 
linguagem. Enquanto a linguagem é a expressão do pensamento, permite que haja um certo intercâmbio entre ambos. O estudo da proposição é exatamente o meio para fundamentar uma teoria do pensamento. Há assim, uma relação estreita entre o pensamento e proposição. Assim como toda proposição com significado expressa um pensamento, todo pensamento terá que ser expressável numa proposição. A linguagem enquanto precisa ser transmitida, precisa para tal do pensamento. Se pensamento e proposição são mutuamente implicativos isto se deve a que proposição é uma figuração dos fatos, como já vimos anteriormente. Os pensamentos são por sua vez figuras que podem expressar-se proposições 3-"pensamento é a figuração lógica dos fatos".

No pensamento a forma da figuração se reduz à forma lógica. Qualquer pensamento pode, em princípio, ser corretamente expresso e interpretado numa proposição. Mas não devemos esquecer que isto se dá tão somente em princípio, pois a linguagem pode disfarçar o pensamento correto (cf. 4.002). Na medida em que a linguagem pode atuar como um disfarce para o pensamento se faz necessário a busca de uma linguagem a mais correta possível para que se possa evitar esta possibilidade. Embora a linguagem corrente esteja em perfeita ordem lógica, sua gramática por nos induzir a erro, dada a sua complexidade. Eis aí o motivo pelo qual Wittgenstein procurou delimitar a possibilidade de uma linguagem logicamente perfeita que pudesse expressar corretamente os pensamentos. Aí se poderia encontrar uma perfeita correspondência entre proposição e pensamento, de modo que sua expressão possa ser unívoca. E isto é o que quer dizer a proposição.

\footnotetext{
3.001 - "Um estado de coisas é pensável” significa: podemos construir-nos uma figuração dele.

4.116 - Tudo em geral o que pode ser pensado o que pode claramente. Tudo o que se deixa exprimir, deixase claramente
}

E aqui entramos depois do que até agora foi dito na distinção fundamental entre "dizer e mostrar".

\section{Dizer e Mostrar a Lógica, o Ético e o Místico}

Tudo que foi dito até aqui procura colocar o verdadeiro problema no centro da filosofia de Wittgenstein. Ou seja, a 
distinção, do ponto de vista lógico, daquilo que é uma teoria, e lembremos que a filosofia não é uma teoria para Wittgenstein; sobre aquilo que pode ser expresso pela linguagem no seu uso proposicional. Isto indicará, em contrapartida, o que pode e não pode ser mostrado por ela. Ou o que pode ser dito por ela com sentido.

Proposições que dizem algo são aquelas que podem ser verdadeiras ou falsas. Vale dizer: quando se indica suas condições de verdade por intermédio dos signos "V" para verdadeiro e " $F$ " para falso e qeu podem pela declaração dessa condição bi-onívoco enquanto condições de possibilidade de sua verdade ou falsidade aparecer como tal.

Dadas as proposições "chove ou faz sol", esquematicamente "p v q ("p" para chove - "q" para "faz sol" e "v" para "ou"). Deixase assim a possibilidade de verdade se reproduzir este modo.

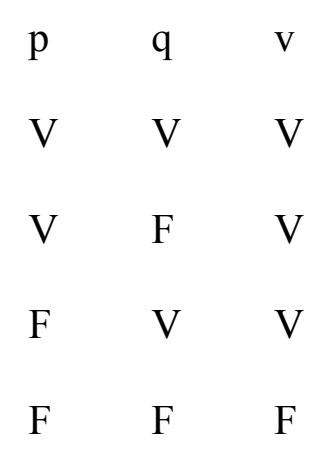

A última coluna sob o signo de disjunção " $v$ " apresenta as condições de verdade das proposições acima citadas: " $p \mathrm{v} q$ " que é a série: VVVF.

Para a conjunção: "Chove ou faz sol"m respectivamente ("p . q"), dizem as respectivas expressões os seguintes valores de verdade, VFFF, pois a conjunção, ou signo proposicional, ambos os componentes das proposições são verdadeiros.

Tais proposições dizem algo, pois para chegarmos à identificação de seus valores de verdade não se considera o símbolo em si mesmo, mas deve-se examinar se elas concordam com a realidade. As proposições "chove ou faz sol" e precisamente falsa se na realidade "chove ou faz sol".

Diferentemente se comportam as proposições as quais contém na última coluna da tabela de verdade os valores $\mathrm{V}$ ou Problemata: R. Intern. Fil. v. 5. n. 1 (2014), p. 64-93 
apenas F. Por exemplo, são as proposições "Chove ou faz sol", como: "chove e não faz chove", respectivamente (" $p \vee \sim p$ "), respectivamente "p. $\sim$ p). A tabela das primeiras condições de verdade da primeira diz o seguinte:

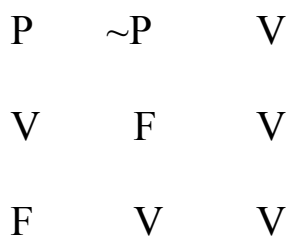

E a seguir a tabela dos valores de verdade da segunda proposição:



No primeiro caso obtivemos a descrição das condições de verdade exclusivamente "V", no segundo caso exclusivamente "F". Às proposições do primeiro tipo chama-as Wittgenstein tautologias, às proposições do segundo tipo contradições. Para identificar os verificar da verdade ou falsidade de semelhantes proposições não é necessário comparálas com a realidade; basta simplesmente considerar seus respectivos valores de verdade. E assim reconhece-se que as tautologias são sempre verdadeiras enquanto as considerações são falsas. Wittgenstein descreve a relação dos diferentes tipos de proposição em:

4.463 - As condições de verdade determinam o campo aberto aos fatos pela proposição.

A proposição, a figura, o modelo são, num sentido negativo, como um corpo sólido que limita a liberdade de movimento do outro, no sentido positivo, como um espaço limitado por uma substância sólida onde o corpo pode ter lugar.

A tautologia deixa inteiramente à realidade o espaço lógico - infinito -, a contradição preenche o espaço lógico inteiro, não deixando à realidade ponto algum.

Problemata: R. Intern. Fil. v. 5. n. 1 (2014), p. 64-93

ISSN 2236-8612 
Nenhuma delas pode, por conseguinte, determina a realidade de um modo qualquer.

A tautologia como a contradição são assim algo como os casos limites da proposição, vale dizer: à rigor, na verdade já não são proposições, pois elas nada dizem, não são figurações, mas elas mostram algo - "A proposição mostra os que mostra, as tautologias não tem qualquer valor de verdade, pois elas são incondicionalmente verdadeiras e as contradições não são sob quaisquer condições imputáveis de verdadeiras.

As tautologias e as contradições são desprovidas de sentido (sinnlos).

4.461 - A proposição mostra o que diz, a tautologia e a contradição que não dizem nada.

A tautologia não possui condições de verdade pois é verdadeira sob qualquer condição; a contradição sobe nenhuma condição é verdadeira. A tautologia e a contradição são vazias de sentido. (Como o ponto de onde duas flechas partem em direções opostas). (nada sei, por exemplo, a respeito do tempo se sei que chove ou não chove).

Tautologia e contradição não tem qualquer sentido porque suas condições de verdade ou seus valores de verdade não podem ser determinados pela realidade.

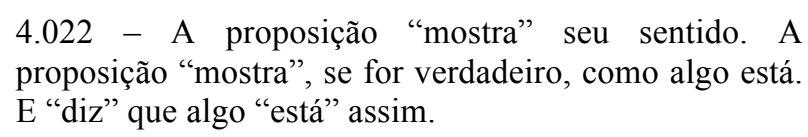
proposição "mostra", se for verdadeiro, como algo está. E "diz" que algo "está" assim.

Propriamente proposições mostram, em comparação com isso, seu sentido, vale dizer, elas mostram como se comportam com os fatos, contanto que elas sejam verdadeiras, e dizem que as coisas (em conformidade com isto) se comportam assim. De que modo é tão importante a distinção entre "dizer e mostrar"? Por que são para Wittgenstein as distinções fundamentais que o Tractatus procura esclarecer?

Parte da resposta deriva-se da idéia de que as proposições enquanto universais e espelho do mundo são as tautologias. 
5.511 - Como é possível a lógica, que tudo abrange e espelha o mundo, precisar de tais artifícios e manipulações especiais? Somente porque tudo isto está ligado a uma rede infinitamente fina, ao grande espelho.

6.1231 - O sintoma da proposição lógica não é a validade universal.

Se universal quer dizer apenas valer para todas as coisas de modo acidental. Uma proposição não universalizada pode ser tautologia tanto quanto uma proposição universalizada.

Vale dizer: sua validade universal não é contingente, mas universal. Somente nos sinais da proposição deixa-se ser vista sobre a realidade empírica, que a linha da condição de verdade apenas confronta.

A lógica deixa-se livremente construir-se com as contradições.

6.1202 - É claro que, em vez da tautologia, é possível empregar a contradição para os mesmos fins.

Que as proposições em enlaces determinados constroem tautologias e respectivamente contradições, mostra algo sobre a forma da linguagem e com isso sobre a lógica da afiguração. Mostra-se assim isto no axioma fundamental. "O que pode ser mostrado não pode ser dito, traduzir-se em palavras.

Apenas o emprego de uma notação lógica suficiente pode dar uma explicação suficiente sobre a essência do lógico, não pode descrevê-la.

Esta concepção, que aparece sempre com novas variações ao longo do "Tractatus" está claramente ligada ao pensamento fundamental, segundo ao "a lógica dos fatos não se deixa apresentar".

4.12 - A proposição pode representar a realidade inteira, não pode, porém, representar o que ela deve ter em comum com a realidade para poder representá-la - a forma lógica.

Para podermos representar a forma lógica seria preciso nos colocar com a proposição fora da lógica, a saber fora, fora do mundo. 
O resultado é mostrado por Wittgenstein na observação em:

6.124 - As proposições lógicas descrevem os andaimes do mundo, ou melhor, os representam. Não "tratam" de nada. Pressupõem que os nomes possuem denotação e as proposições elementares, sentido. E tal é a sua vinculação com o mundo. É claro que isso deve indicar alguma coisa a respeito do mundo, que certas vinculações de símbolo - que essencialmente possuem um caráter determinado - são o decisivo. Dissemos que, nos símbolos que usamos, muito era arbitrário, muito não o era. E na lógica apenas isso exprime? O que quer dizer que na lógica "nós" não exprimimos o que queremos com a ajuda de signos, mas que a natureza dos signos naturalmente necessários na lógica, assertase a si próprio. Ai conhecermos a sintaxe lógica de uma linguagem simbólica qualquer, já estão dadas todas as proposições da lógica.

A flagrante distinção entre dizer e mostrar desempenha não apenas, em conexão com a doutrina do sentido da proposição e a lógica das afigurações, um papel, mas tem um lado mais alargado: conduz ao pensamento conclusivo do Tractatus.

É isto o que recorda Wittgenstein numa carta a Ficker de novembro ou outubro de 1919:

"O sentido do livro é um sentido ético. Minha obra consiste em duas partes, a que aqui apresento e a que não escrevi. O ético é delimitado por meu livro, por assim dizê-lo desde dentro; e estou convencido de que, estritamente, só assim pode delimitar-se".

Wittgenstein procura traçar os limites do ético com a conseqüência de calar sobre ele ali onde terá que haver falado sobre ele; tais limites ficam pois, mostrados. E este é o sentido fundamental do Tractatus: mostrar o pouco que se consegue quando se soluciona os problemas dos quais trata, pois o realmente importante são os problemas éticos, como o sentido da vida, e sobre isso nada se pode dizer. O mesmo poder-se-ia dizer do místico ${ }^{3}$.

7- Do que não se pode falar, deve-se calar. 


\section{Bibliografia}

WITTGENSTEIN, L. "Tractatus Lógico-Philosophicus. Trad. José A. Giannotti: Companhia Editora Nacional/Editora de U. de São Paulo, São Paulo, 1968.

Philosophical Investigations. Trad. G.E.M./Anscombe. Basil Blacwell, Oxford, 1953.

Werkausgabe Band 1.

CHAUVIRÉ, C. Wittgenstein. Jorge Zhar Editor; Rio de Janeiro, 1991.

STENIUS, Erik. Wittergenstein's Tractatus. A Critical Exposition of its Main Lines of Thought. Basil Blacwell. Oxford, 1964.

FANN, K.T. El concepto de Filosofia en Wittgenstein. Editora Tecnos. Madrid, 1975.

\footnotetext{
Notas

1 (Wittgenstein - Werkausgabe, Band 8 - pga. 463-4; Suhkamp Verlag, Frankfurt a. Main. 1984).

2 (Investigações Filosóficas. (§-109).

${ }^{3}$ (cf. HADOT, P. Wittgenstein y los limites del lenguaje. Valência, PRETEXTOS, 2007).
} 